\title{
Implementation of Solar-PV Inverter as STATCOM during Nighttime in Grid-Connected System (PV-STATCOM)
}

\author{
Indraman Tamrakar ${ }^{1}$, Kishor Joshi ${ }^{1}$, Pranisha Karki ${ }^{1}$, Sagar Bimali ${ }^{1}$, Tara Aryal ${ }^{1, *}$ \\ ${ }^{I}$ Department of Electrical Engineering, Pulchowk Campus, Institute of Engineering, Tribhuvan University, Lalitpur, \\ Nepal \\ Corresponding Email: 071bel346epcampus.edu.np
}

\begin{abstract}
:
Grid-connected PV-system generates active power only during daytime and it remains completely idle or sleeping during nighttime. In an interconnected power system balance between active and reactive power consumption and generation is very essential to maintain the frequency and voltage constant. The current trend is that the reactive Power is either supplied by generators or by separate reactive Power compensators such and shunt capacitor, STATCOM, etc. If the grid needs reactive power during night time, the sleeping inverter of the solar-PV system can be used as a reactive power generator without exceeding the volt-amp rating of the inverter and this scheme is named PV-STATCOM in this paper.

This paper presents the concept of PV-STATCOM and its control logic. The inverter of the grid-connected Solar-PV system acts as an active power generator during daytime and reactive power generator during nighttime. The proposed scheme is simulated in MATLAB Simulink and the simulation results are presented. The simulation result shows that the proposed control logic for PVSTATCOM works satisfactorily.
\end{abstract}

Keywords: Static Synchronous Shunt Compensator (STATCOM), Photovoltaic (PV), Reactive Power Control, Flexible AC Transmission System (FACTS), Solar Power Systems.

\section{Introduction}

Although PV technology is expensive, it is receiving strong encouragement through various programs [1]. But the main challenges the renewable system faces are integrating on a large scale due to their limited power transfer capability [2].

To increase the available power transfer capability (ATU) of the existing line, FACTS devices are being considered $[3,4]$. FACTS devices that are used to increase the ATU of the existing line are STATCOM, SSC, Capacitor Bank, etc. Due to the flexibility in operation, wide availability of power electronic devices and fast response STATCOM is mostly used. For small and medium power applications, compensation of VAR has been proposed using IGBT i.e. insulated gate bipolar transistor as switching devices $[5,6]$. Hysteresis Band controller inverter is used to track the actual current to compensate for the reactive power. A new voltage control has also been proposed on PV solar farms to act as STATCOM $[7,8,9]$. But this does not have utilized PV system for power transfer limit improvement.

This paper proposes active and reactive power control to balance the total capacity of inverter and adjust the reactive power for PV Power. During the daytime, it acts as an active and reactive power generator. At nighttime, the PV system is disconnected, and the operation will be just STATCOM in parallel with the grid.

The paper is organized as follows; Section 2 presents the basic concept of PV-grid connected system and STATCOM operation. Section 3 presents the basic concept of the Proposed Scheme. Section 4 presents simulation results performed in MATLAB/Simulink. Section 5 discusses the discussion and conclusion of the paper.

\section{Grid-Connected Solar PV System and STATCOM}

\section{$2.1 \quad D-Q$ Theory}

It will be very complex to analyze the system in abc component. To simplify this complication, DQ- modelling had been developed.

$\mathrm{abc}$ to $\mathrm{dq} 0$ transformation gives,

$$
\left[\begin{array}{l}
I_{d} \\
I_{q} \\
I_{o}
\end{array}\right]=\sqrt{\frac{2}{3}}\left[\begin{array}{ccc}
\cos \theta & \cos \left(\theta-\frac{2 \pi}{3}\right) & \cos \left(\theta-\frac{4 \pi}{3}\right) \\
-\sin \theta & -\sin \left(\theta-\frac{2 \pi}{3}\right) & -\sin \left(\theta-\frac{4 \pi}{3}\right) \\
\frac{1}{\sqrt{2}} & \frac{1}{\sqrt{2}} & \frac{1}{\sqrt{2}}
\end{array}\right]\left[\begin{array}{l}
I_{a} \\
I_{b} \\
I_{c}
\end{array}\right]
$$




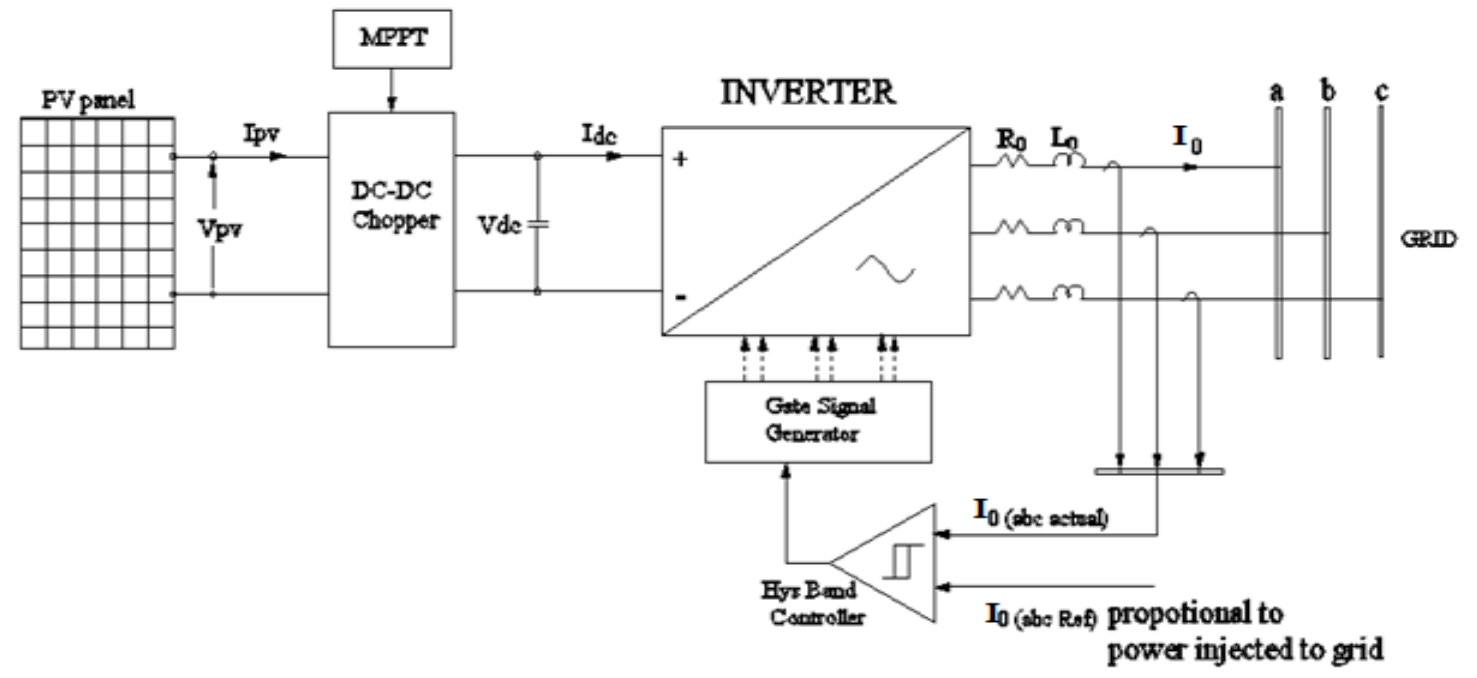

Figure 1: Grid Connected Solar PV System

Q-axis coil current $\mathrm{I}_{\mathrm{q}}$ will not produce a magnetic tie-up between the stator pole and rotor pole. Whereas d-axis coil current $I_{d}$ produces magnetic tie-up between stator pole and rotor pole. Therefore, $I_{d}$ is proportional to Active power $(\mathrm{P})$ and $\mathrm{I}_{\mathrm{q}}$ is proportional to Reactive power $(\mathrm{Q})$.

\subsection{Grid-Connected Solar PV System}

Grid-Connected Solar PV System consists of PV Panel, MPPT, DC Chopper/VSI, Inverter, RL filter, Hysteresis Band Controller, and Gate Signal Generator. Figure 1 shows the block diagram of the Grid connected Solar PV System.

\subsection{1 $\quad$ MPPT}

The efficiency of the PV-system is low in the order of 18$20 \%$, therefore PV needs maximum power point tracking (MPPT) control to extract maximum power $\left(\mathrm{P}_{\max }\right)$ from the solar PV-system [10]. The PV and IV Characteristics curve along with the maximum power point is as shown in figure 2.

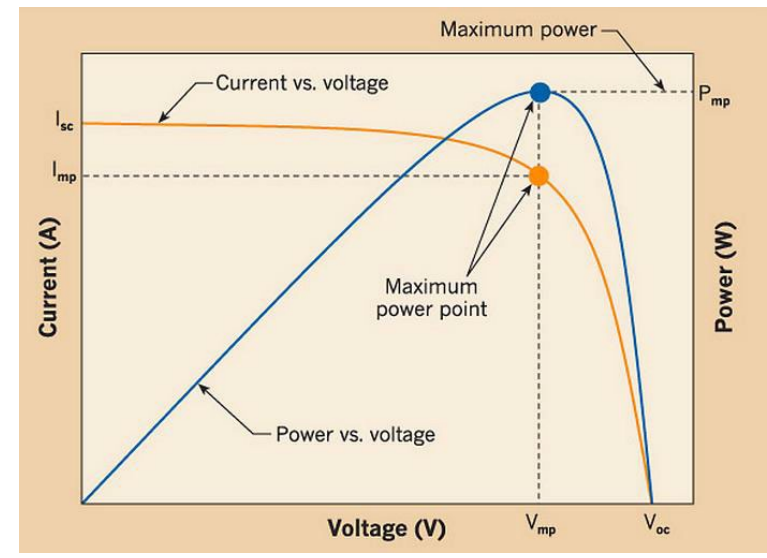

Figure 2: PV and IV Characteristics Curve
There are many MPPT controls developed. The P\&O (Perturb and observe) algorithm is very popular, simple and it requires less parameter to track the maximum power from PV source under different condition, among all other MPPT techniques.

The flow chart of the corresponding algorithm is shown in figure 3. In which, when there is an increase in photovoltaic power (P) and photovoltaic voltage (V) takes place at the same time and vice versa, a disruption in step size $(\Delta \mathrm{D})$ will be added to the duty cycle, duty cycle (D) to generate next cycle of perturbation to force the operating point moving towards the maximum power point. When there is an increase in photovoltaic power but a decrease in photovoltaic voltage and vice versa, then disruption in step size will be decreased for the next cycle of perturbation. This process will repeat until to obtain maximum power at the maximum power point. It satisfies the good dynamic response and steady-state performance.

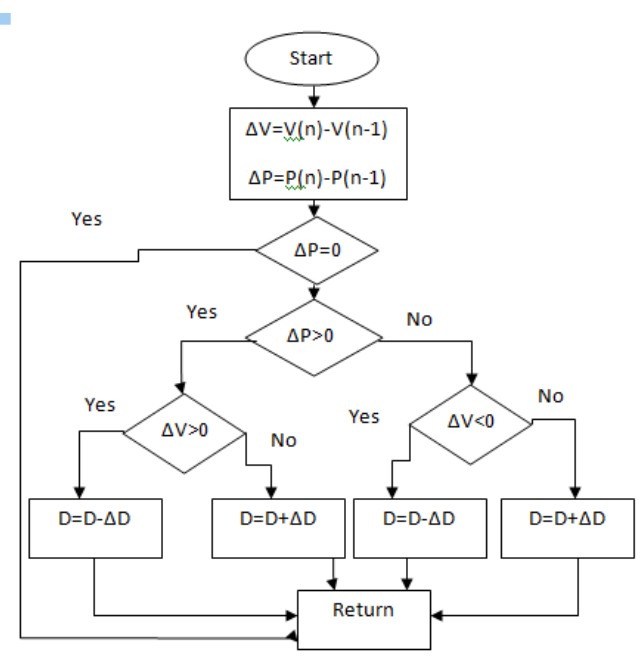

Figure 3: Flow Chart of Perturb and Observe Algorithm 


\subsubsection{CONTROL LOGIC}

Figure 4 depicts the control logic for reference current calculation. MPPT logic estimates the maximum power $\left(\mathrm{P}_{\max }\right)$ that can be extracted from the PV panel for the given value of solar irradiance. $\mathrm{I}_{d}$ current (d-axis current to be injected by the inverter to the grid for maximum power transfer to the grid) is found from VSI dc-link controller. Since the Inverter is supposed to inject only active power, $\mathrm{I}_{\mathrm{q}}$ current ( $\mathrm{q}$-axis current to be injected by the inverter) is set to Zero. PLL block is used to sense the grid frequency. DQ0 to abc transformation blocks gives the reference to current $I_{a b c}$ (ref) to be injected by the inverter to the grid. The actual as side inverter current $I_{a b c}$ (actual) is sensed and compared with $I_{a b c}$ (ref) in the hysteresis band controller. The hysteresis band controller along with the gate signal generator produces required gate signals for a 3-phase bridge inverter so that the $I_{a b c}$ (actual) tracks the $I_{a b c}$ (ref) within the set band and insures the injection of maximum active power to the grid.

\subsection{STATCOM as shunt VAR Generator and Hysteresis Band Inverter}

Figure 5 and 6 represent the block diagram of STATCOM as VAR generator and phasor diagram of STATCOM, respectively.

In STATCOM, $\widetilde{I_{0}}=\frac{\widetilde{V_{s}}-\widetilde{V_{O}}}{R_{o}+j X_{O}}$

Power loss in $\mathrm{R}_{\mathrm{o}}$ per phase $=I_{o}^{2} * R_{o}$

Active power flow in the inverter branch $=V_{S} * I_{o} * \sin \theta_{o}$

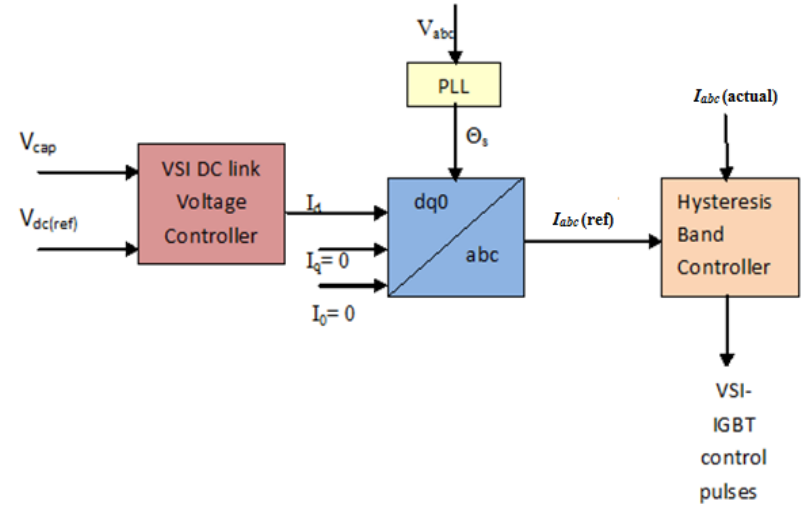

Figure 4: Control Logic for $I_{r}$ Calculation

If $I_{o}^{2} * R_{o}=V_{S} * I_{o} * \sin \theta_{o}$ then active power flow in the inverter is exactly equal to power loss in the inverter branch. This happens for the value of $\theta_{0}$, which is given by, $\theta_{o}=\sin ^{-1}\left(\frac{R_{o} I_{o}}{V_{s}}\right)$. After some time $\theta_{\mathrm{o}}$ becomes steady.

If $\theta_{0}$ of inverter $>\theta_{0}$ (steady) then active power flow in inverter branch and $\mathrm{V}_{\mathrm{dc}}$ of capacitor increases. If $\theta_{\mathrm{o}}$ of inverter $<\theta_{0}$ (steady) then active power from inverter and $\mathrm{V}_{\mathrm{dc}}$ decreases.

Therefore, $\theta_{0}$ can be controlled to the desired value by sensing ' $\mathrm{V}_{\mathrm{dc}}$ ' and comparing it with reference value $\mathrm{V}_{\mathrm{dc}}$ (ref). The error obtained is then passed through PI controller which gives a proper value of $I_{d}$ at which value of active power flow in inverter be exactly equal to $I_{o}^{2} *$ $R_{O}$ and $\mathrm{V}_{\mathrm{dc}}$ remains constant.

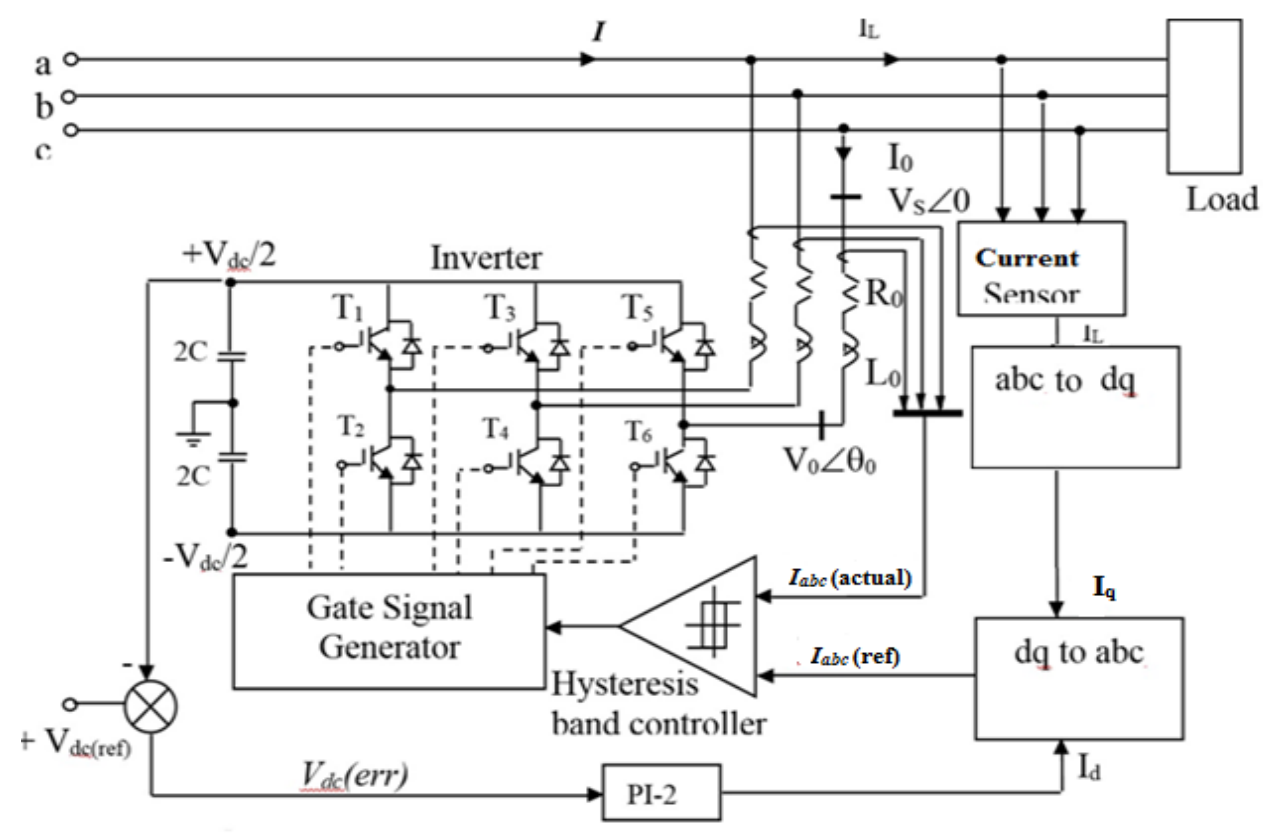

Figure 5: STATCOM as Var Generator 


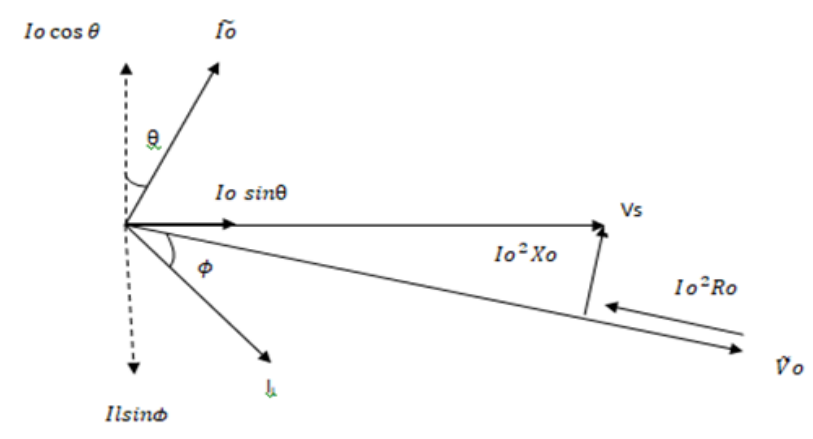

Figure 6: Phasor Diagram of STATCOM

From the figure 5, the amount of reactive power from STATCOM (or $\mathrm{I}_{\mathrm{q}}$ which is a 90 -degree leading current) can be generated by sensing the load current through current sensor. $I_{q}$ part of that current can be made the $I_{q}$ component of the STATCOM. These $\mathrm{I}_{\mathrm{q}}$ and $\mathrm{I}_{\mathrm{d}}$ currents are then converted into $\mathrm{I}_{\mathrm{abc}}$ (ref) using the PLL block. The actual as side inverter current $I_{a b c}$ (actual) is sensed and compared with $\mathrm{I}_{a b c}$ (ref) in the hysteresis band controller. The hysteresis band controller along with the gate signal generator produces required gate signals for a 3-phase bridge inverter so that the $I_{a b c}$ (actual) tracks the $I_{a b c}($ ref) within the set band and insures the injection of required reactive power demanded by the load.

When the $T_{1}$ switch is turned ON keeping $T_{2}$ OFF, the inverter voltage output is $+0.5 \mathrm{~V}_{\mathrm{dc}}$, and $i_{0}$ rises as shown in figure 7 . When the actual current $\left(i_{0}\right)$ reaches the upper band (UB) limit, the $T_{1}$ is turned OFF and the switch $T_{2}$ and $\mathrm{T}_{4}$ turned $\mathrm{ON}$, then output voltage becomes $-0.5 \mathrm{~V}_{\mathrm{dc}}$ and $i_{0}$ decay slowly. When the actual current $\left(i_{0}\right)$ reaches the lower band (LB), the switch $T_{2}$ is turned off and the switch $T_{1}$ is turned on, then output voltage becomes
$+0.5 \mathrm{~V}_{\mathrm{dc}}$ and $i_{0}$ rises again. As a result, the output voltage oscillates from $+0.5 \mathrm{~V}_{\mathrm{dc}}$ to $-0.5 \mathrm{~V}_{\mathrm{dc}}$, and the actual current track the reference current within the set hysteresis band (HB).

\section{Proposed Scheme}

There are two modes of PV-STATCOM operation:

Partial PV-STATCOM mode: In this mode, the real power generation continues unabated based on available solar radiation. The inverter capacity left after real power generation is used for STATCOM operation. This mode is used during the daytime typically during the early morning and late afternoon.

Full STATCOM mode: This mode utilizes the entire capacity of the solar inverter to operate as a STATCOM. This mode is completely available during nighttime.

\subsection{Control logic}

Figure 8 illustrates the block diagram of the control logic of PV-STATCOM using Hysteresis Band Controller.

\section{During daytime, $I_{r(p v)}>I_{r(p v)(T h r e s h o l d)}$}

At this time PV array supplies active power this active power is transferred to the grid using $\mathrm{V}_{\mathrm{dc}}$ controller, Inverter, and other control logic. At that time, the reactive power is supplied to the grid if the power generated by the $\mathrm{PV}$ array is not the maximum of its limit (which is at $1000 \mathrm{~W} / \mathrm{m}^{2}$ generally). The total power (VA) of the Inverter is always constant. CB-1 and CB-2 are kept closed at daytime according to irradiance.

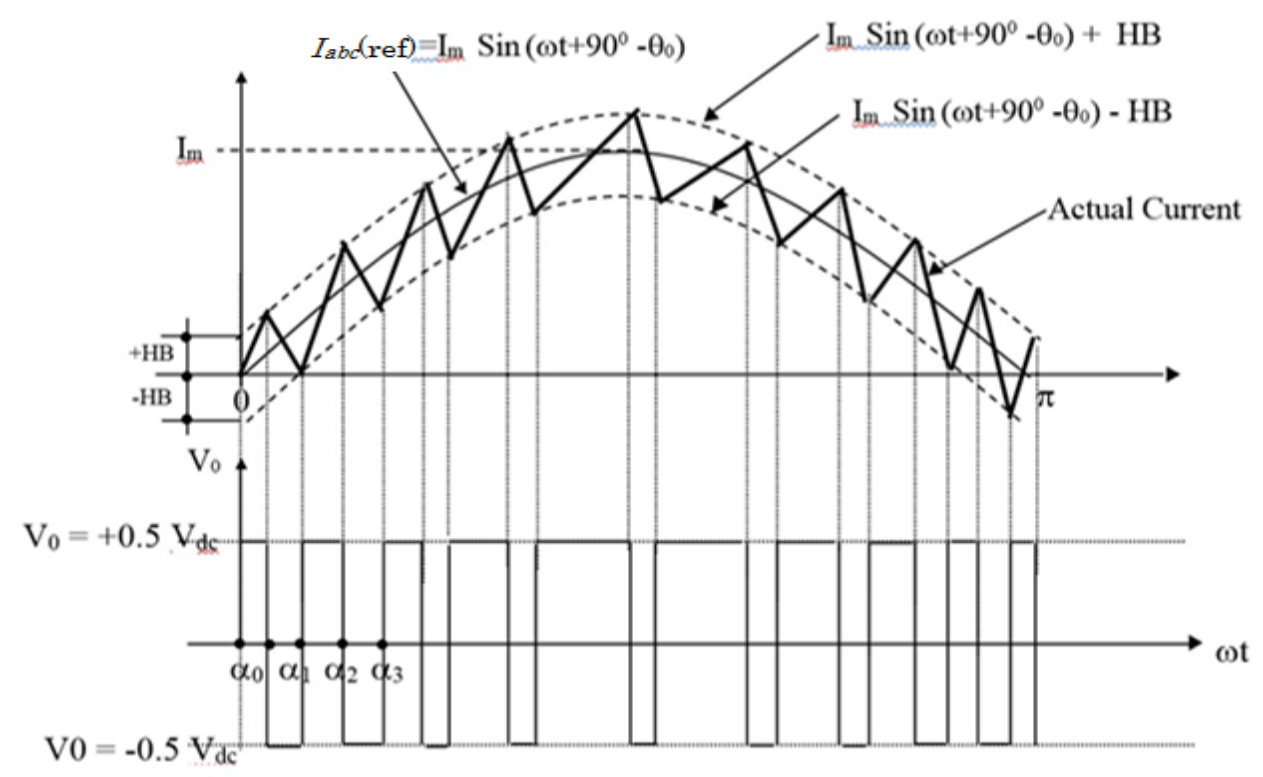

Figure 7: Current Tracking in Hysteresis Band 


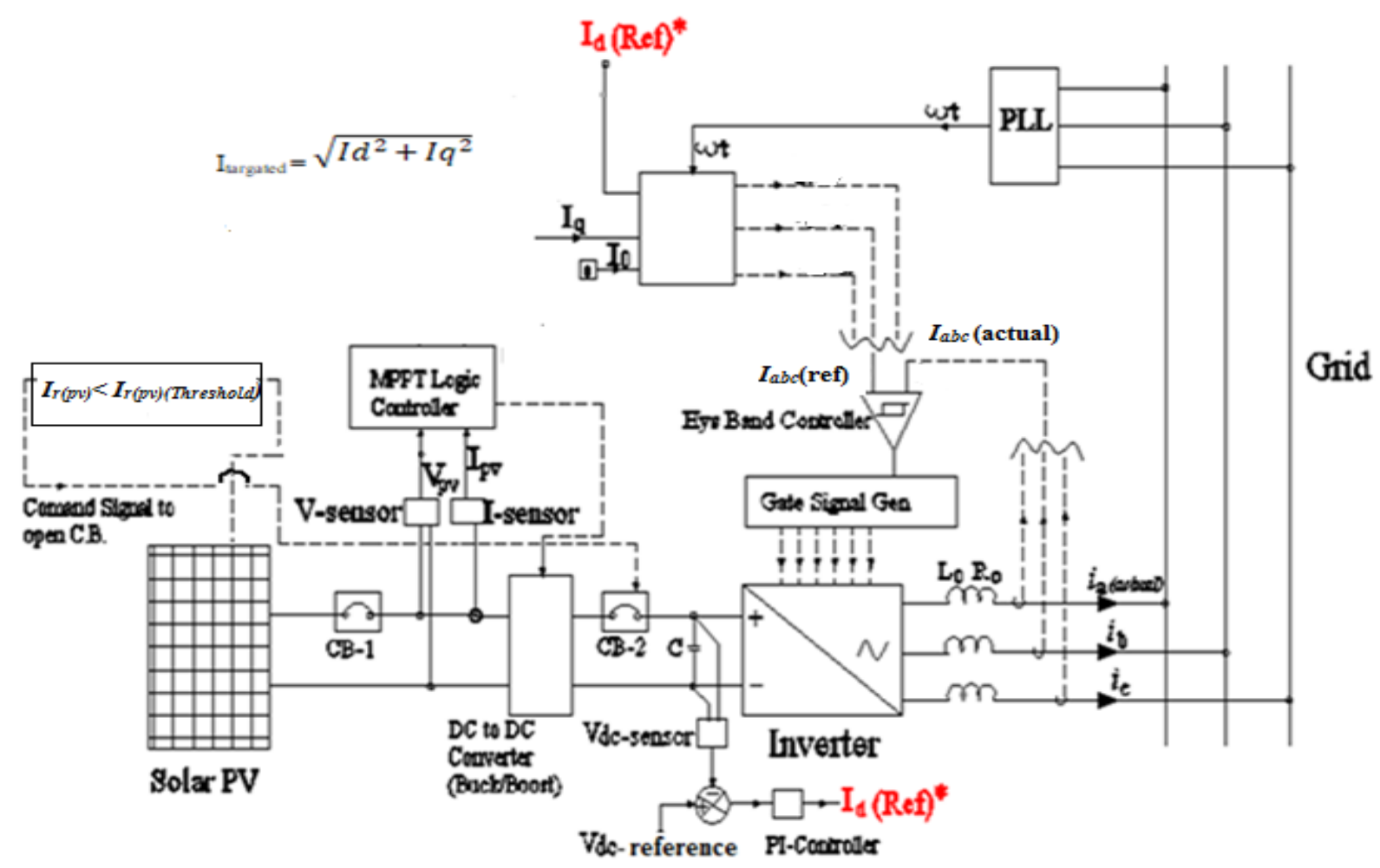

Figure 8: Control logic of PV-STATCOM

\section{During nighttime, $I_{r(p v)}<I_{r(p v)(T h r e s h o l d)}$}

At night Irradiance level is below the threshold CB-1 and CB-2 are kept open so that there is no power flow from the PV array. At this time, the inverter supplies only reactive power to the grid keeping total power (VA) constant. $\mathrm{I}_{\text {targeted }}$ value is taken as maximum power delivered by the PV array as total power or we can take it as according to devices used in circuit. This $\mathrm{I}_{\text {targeted }}$ value is now linked with $\mathrm{I}_{d}$ (active component) and $\mathrm{I}_{\mathrm{q}}$ (reactive component) to calculate how much active and reactive power to supply.

\section{Simulation and Results}

\subsection{Simulation}

The model as shown in figure 9 is simulated using MATLAB (Matrix laboratory) simulation software (2016a).

\subsection{System Parameters}

Table 1 and 2 illustrates the specification of PV and inverters respectively used in the simulation. Likewise, the data of boost converter and coupling inductor is as presented in the table 3 and 4 . For the calculation of d-axis component of current $I_{d}$, the data used are as shown in Table 5.
Table 1: PV specifications

\begin{tabular}{|l|l|}
\hline Components & Parameters \\
\hline Module & $\begin{array}{l}\text { Sun Power SPR- } \\
315 \mathrm{E}-\mathrm{WHT}-\mathrm{D}\end{array}$ \\
\hline Maximum Power $\left(\mathrm{P}_{\max }\right)$ & $315.072 \mathrm{~W}$ per string \\
\hline Open Circuit Voltage $\left(\mathrm{V}_{\mathrm{OC}}\right)$ & $64.6 \mathrm{~V}$ per string \\
\hline Voltage at Max Power Point $\left(\mathrm{V}_{\mathrm{mp}}\right)$ & $54.7 \mathrm{~V}$ per string \\
\hline Short Circuit Current $\left(\mathrm{I}_{\mathrm{sc}}\right)$ & $6.14 \mathrm{~A}$ per string \\
\hline Current at Max Power Point $\left(\mathrm{I}_{\mathrm{mp}}\right)$ & $5.76 \mathrm{~A}$ per string \\
\hline Irradiance $\left(\mathrm{I}_{\mathrm{r}}\right)$ & $1000 \mathrm{~W} / \mathrm{m}^{2}(\mathrm{max})$ \\
\hline
\end{tabular}

Table 2: Inverter

\begin{tabular}{|l|l|}
\hline Components & Parameters \\
\hline Inverter Rating & $82.5 \mathrm{KVA}$ \\
\hline Capacitor Rating & $10 \mathrm{mF}$ \\
\hline Capacitor Voltage & $350 \mathrm{~V}$ \\
\hline
\end{tabular}

Table 3: Boost Converter data

\begin{tabular}{|c|c|}
\hline Components & Parameters \\
\hline Converter Rating & $\mathbf{8 2 . 5 K V A}$ \\
\hline Inductor Rating & $4 \mathrm{mH}$ \\
\hline
\end{tabular}




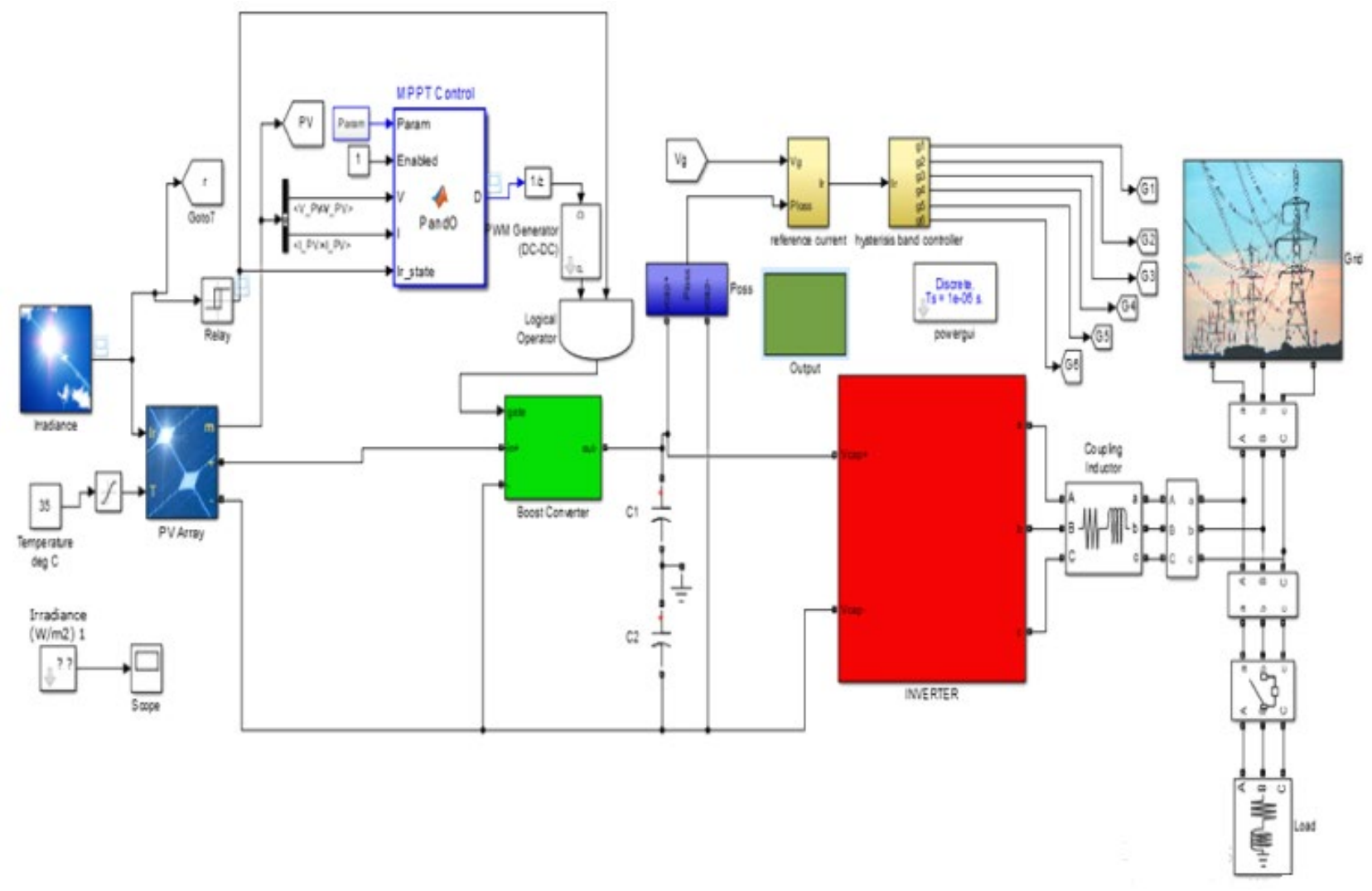

Figure 9: Simulation Model of PV-STATCOM in MATLAB/simulink

Table 4: Coupling Inductor

\begin{tabular}{l|l} 
Components & Parameters \\
\hline Resistance & $0.01 \mathrm{Ohm}$ \\
\hline Inductance & $0.28 \mathrm{mH}$
\end{tabular}

Table 5: Data used for $I_{d}$ current calculations

\begin{tabular}{l|l} 
Components & Parameters \\
\hline Reference Voltage & $700 \mathrm{~V}$ \\
\hline $\mathrm{K}_{\mathrm{p}}$ & 11.2 \\
\hline $\mathrm{K}_{\mathrm{i}}$ & 73.5 \\
\hline Sample Time & $1 \mathrm{e}-5$
\end{tabular}

\subsection{Results}

The total voltage across the DC- link capacitor was held almost constant at $700 \mathrm{~V}$. Dump power obtained from the inverter terminals was passed to the grid with the expense to maintain the constant dc-link voltage. The dc-link voltage is to be maintained constant at some suitable value because the fluctuation of this voltage changed the output of the inverter. Figure 10 shows the total DC- link voltage at $700 \mathrm{~V}$.
According to the control logic used for power extraction from $\mathrm{PV}$, if irradiance $<200 \mathrm{~W} / \mathrm{m}^{2}$, it is considered as nighttime, while if irradiance $>200 \mathrm{~W} / \mathrm{m}^{2}$, it is considered as daytime. Irradiance signal is constructed with respect to time showing daytime (when irradiance $>200 \mathrm{~W} / \mathrm{m}^{2}$ ) and nighttime (when irradiance $<200 \mathrm{~W} / \mathrm{m}^{2}$ ). From the figure 11 , in the initial situation, when irradiance is maximum $\left(1000 \mathrm{~W} / \mathrm{m}^{2}\right.$ according to our logic), MPPT tracks maximum power at that instant, and active power of full capacity is obtained from PV after a certain transient. The transient is due to delay in electronic switching components. When irradiance has decreased from $1000 \mathrm{~W} / \mathrm{m}^{2}$, active power generation has also decreased. At the same instant reactive power has also gradually increased such that apparent power is constant which is clearly seen at the graph. When irradiance $<200 \mathrm{~W} / \mathrm{m}^{2}$ there is no active power generation. This is the nighttime according to our logic. At this time inverter acts as VAR generator and generates VAR in full capacity. The similar process is followed where active and reactive power flows in such a way that apparent power is always constant. During daytime, either active power only or both active and reactive power flows according to the situation whereas, during nighttime only reactive power is supplied by the inverter. 


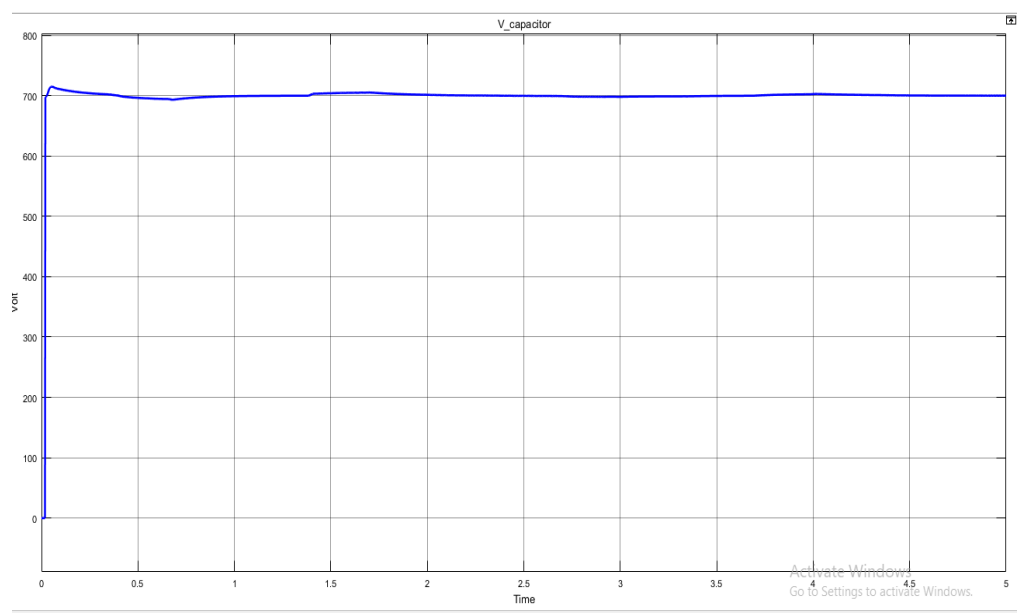

Figure 10: Capacitor Voltage with respect to Time
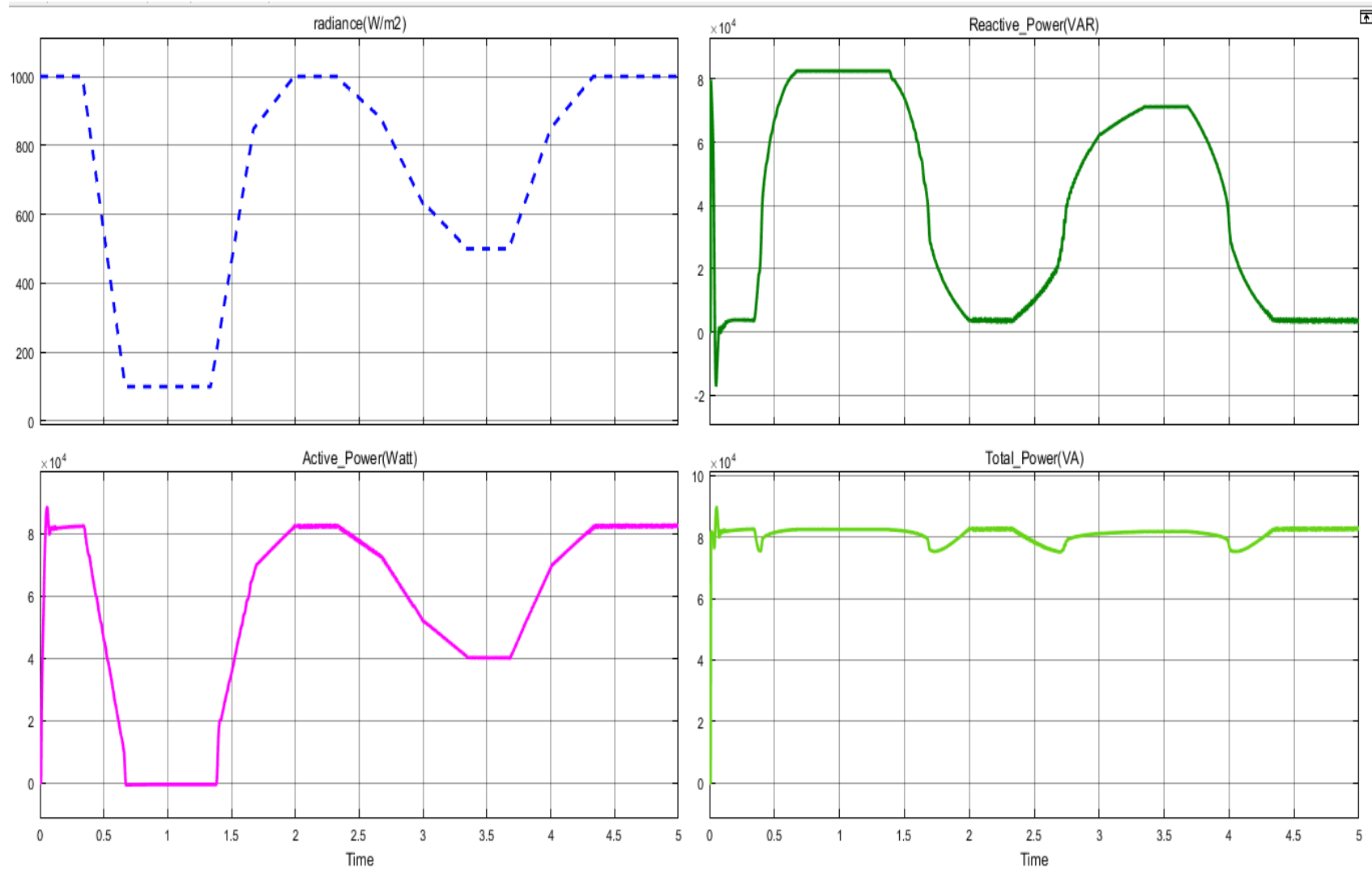

Figure 11: Irradiance, Active power, Reactive power, and Total power with respect to Time

Figure 12 illustrates the magnified view of actual current and reference current per phase. It shows that the actual current is tracked within the hysteresis band. The hysteresis band is taken 10 percentage of reference current. In the figure 13, when current is tracked voltage is sinusoidal. There are two limits in above graph; this is due to tracking of current within hysteresis band. Figure 14 and 15 shows the inverter current and voltage plot with respect to the time respectively. From the figure 16 it is observed that $I_{d}$ current is being tracked according to the changing value of irradiance and from figure $17 \mathrm{I}_{q}$ current is found to be high when Id current is low and vice versa.

\section{Discussion and Conclusion}

Generally solar inverter is only used at daytime to generate the active power for the resistive load. For the inductive load separate reactive power compensator like STATCOM, capacitor is to be installed in interconnected system. To replace these compensators, we used inverter as VAR generator. 


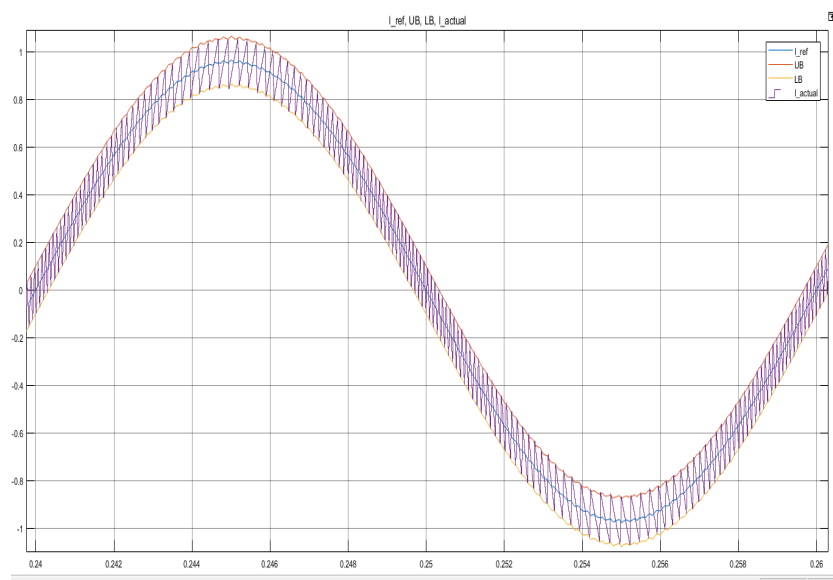

Figure 12: Magnified View of Current showing Hysteresis Band

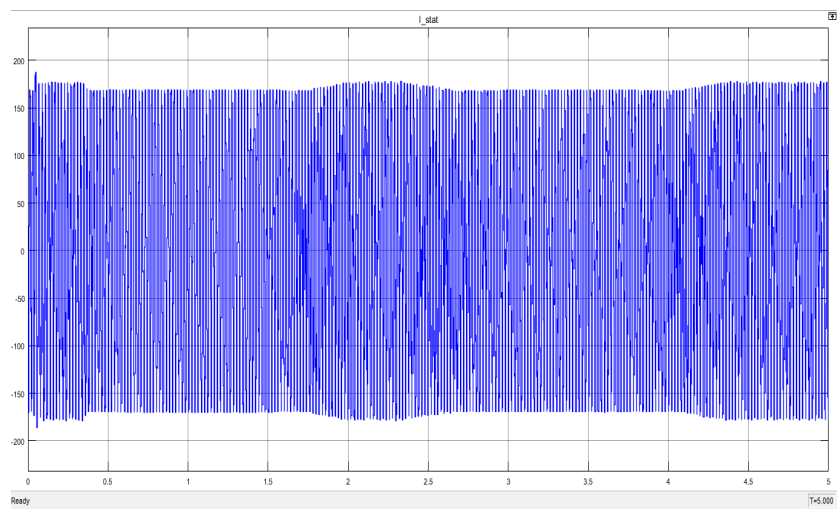

Figure 14: Inverter Current with respect to Time

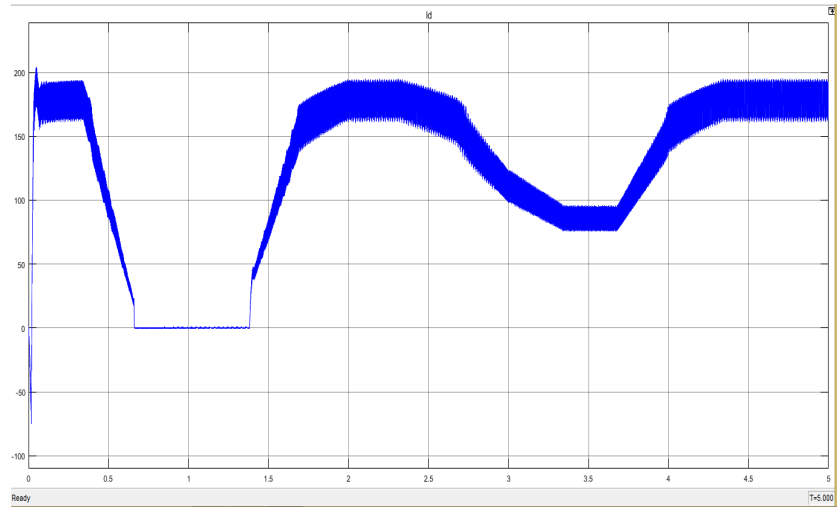

Figure 16: Id Current for Reference Current

We used DQ model theory to apply our idea in this project. During daytime, MPPT tracks the maximum power for the available irradiance and temperature to supply active power

By keeping the inverter capacity constant remaining power is used to supply reactive power using inverter as STATCOM. If the irradiance is below certain threshold

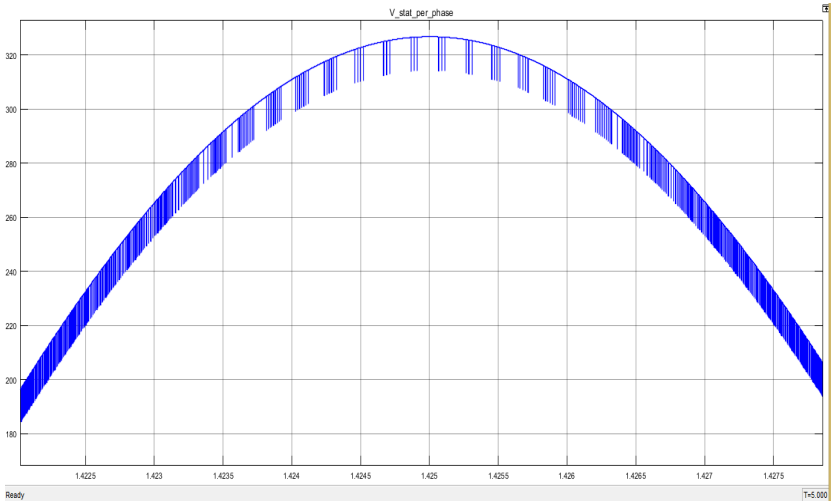

Figure 13: Magnified View of Inverter Voltage

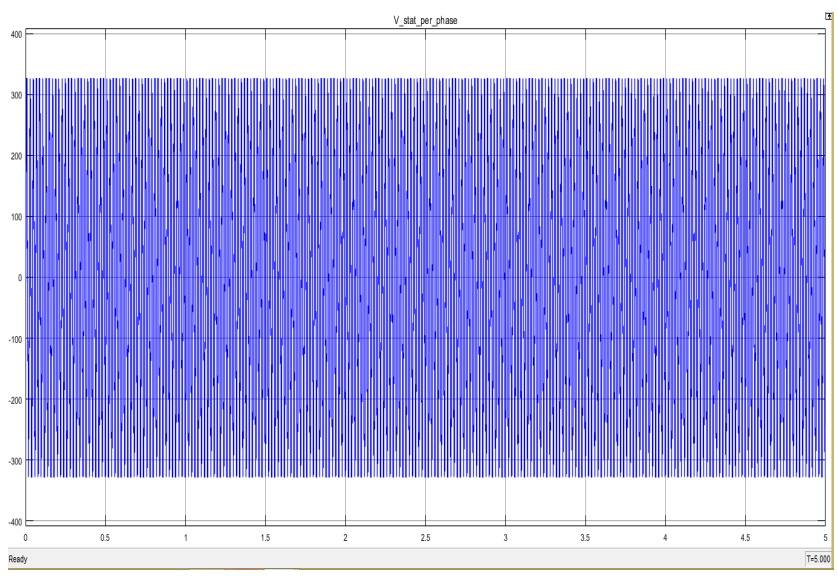

Figure 15: Inverter Voltage per phase with respect to Time

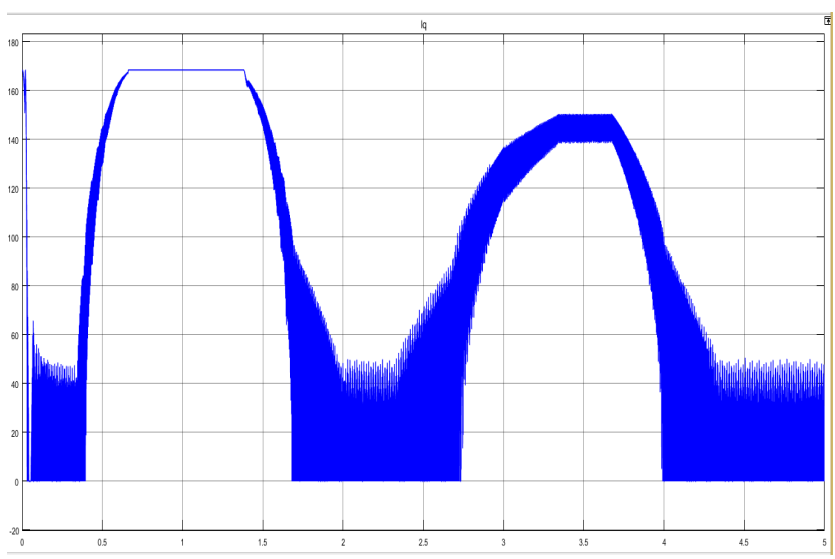

Figure 17: $I_{q}$ Current for Reference Current

value $\left(200 \mathrm{~W} / \mathrm{m}^{2}\right)$, inverter supplies only reactive power even in the daytime. Similarly, during nighttime it only operates as reactive power generator at full capacity. By doing this on one side, we can make full use of inverter in the nighttime and in the daytime without sun. On the other side, the required reactive power needed in the interconnected system is supplied without any extra cost of installation of capacitor. This system is most 
economical in sector of high load factor and constant reactive power consumer.

\section{Acknowledgment}

This research paper was supported by the Department of Electrical Engineering, Central Campus, Pulchowk. The authors are thankful to all the professors and lecturers of the department for the precious comment and kind suggestion throughout the project duration. The authors would also like to show gratitude to the RETRUD-2018 for providing this opportunity.

\section{References}

[1] Rajiv K. Varma, Graham Sanderson and Ken Walsh, "Global PV Incentive Policies and Recommendations for Utilities", Proc. of IEEE Canadian Conference on Electrical and Computer Engineering 2011, Niagara Falls, Canada, May 2011.

[2] Hong Shen, Hai Wei Li, Bin Huang, Jing Li, "Study on Integration and Transmission of Large Scale Wind Power in JiuQuan Area Gansu Province China," in Proc. 2009 CIGRE/IEEE PES Joint Symposium on Integration of Wide-Scale Renewable Resources into the Power Delivery System

[3] R. M. Mathur and R. K. Varma, "Thyristor-Based FACTS Controllers for Electrical Transmission Systems", New York: Wiley-IEEE Press, 2002

[4] Shah Arifur Rahman, Rajiv K. Varma and Wayne Litzenberger, "Bibliography of FACTS Applications for Grid Integration of Wind and PV Solar Power Systems: 1995-2010, IEEE Working Group Report”, Paper 2011GM1483, Accepted for Presentation in the IEEE PES General Meeting, Detroit, USA, July 2011.

[5] K. Chatterjee, B. G. Fernandes, and G. K. Dubey, "An instantaneous reactive volt-ampere compensator and harmonic suppressor system", IEEE Transaction on Power Electronics, vol. 14, no. 2

[6] I. Tamrakar, L. B. Shilpakar, B. G. Fernandes and R. Nilsen, "Voltage and frequency control of parallel operated synchronous generator and induction generator with STATCOM in micro hydro scheme," in IET Generation, Transmission \& Distribution, vol. 1, no. 5, pp. 743-750, September 2007. doi: 10.1049/ietgtd:20060385

[7] R.K. Varma, S A Rahman, and R. Seethapathy, "Novel Control of Grid Connected Photovoltaic (PV) Solar Farm for Improving Transient Stability and Transmission Limits Both During Night and Day," in Proc. 2010 World Energy Conference, Montreal, Canada, pp. 1-6.
[8] R. K. Varma, V. Khadkikar, and R. Seethapathy, "Nighttime application of PV solar farm as STATCOM to regulate grid voltage," IEEE Transactions Energy Conversion, vol. 24, no. 4, pp. 983-985, 2009.

[9] R. K. Varma, Shah Arifur Rahman, Mahendra A.C., Ravi Seethapathy and Tim Vanderheide, "'Novel Nighttime Application of PV Solar Farms as STATCOM (PVSTATCOM)'", Proc. 2012 IEEE PES General Meeting at San Diego, USA, July 2012.

[10] Nisha Sharma, Deepak Dalal, "Efficiency and Result Analysis of 50Kw Grid Connected PV System Using MATLAB/SIMULINK", International Journal of Advanced Research in Electrical, Electronics and Instrumentation Engineering, Vol. 4, Issue 10, pp.82008206, October 2015. 